\title{
Post-Operative Pain Management Practices in Patients with Dementia - The Current Situation in Finland
}

\author{
Maija Rantala ${ }^{*}$, , Päivi Kankkunen ${ }^{1}$, Tarja Kvist ${ }^{1}$ and Sirpa Hartikainen ${ }^{2}$ \\ ${ }^{I}$ Department of Nursing Science, Kuopio Campus, University of Eastern Finland, Finland \\ ${ }^{2}$ Department of Clinical Pharmacology, School of Pharmacy, Kuopio Campus, University of Eastern Finland, Finland
}

\begin{abstract}
The aim of this study is to describe current post-operative pain management practices for patients with dementia and hip fracture in Finland. Older adults with hip fracture are at high risk of under treatment for pain, especially if they also have a cognitive disorder at the stage of dementia. Previous studies have provided limited information about the quality of acute pain treatment for persons with dementia. In this study data concerning current pain management practices was collected by questionnaire from 333 nursing staff. They worked in surgical wards of seven universities and ten city-centre hospitals. The response rate to the questionnaire was $53 \%$. The data was analysed using factor analysis and parametric methods. Half the respondents $(53 \%)$ considered that post-operative pain management was sufficient for patients with dementia. Less than one third of respondent nurses reported that pain scales were in use on their unit: the most commonly used scale was VAS. The use of pain scales was significantly related to the respondents' opinion of the sufficiency of post-operative pain management in this patient group $(p<0.001)$. The findings can be utilised in nursing practice and research when planning suitable complementary educational interventions for nursing staff of surgical wards. Further research is needed to explain the current situation of pain management practices from the viewpoint of patients with dementia.
\end{abstract}

Keywords: Pain, dementia, hip fractures, post-operative pain, nursing staff.

\section{INTRODUCTION}

Hip fractures are common amongst the older population. Fractured hips account for over 7000 injuries in Finland annually [1] and approximately $21-25 \%$ of these patients have at least moderate cognitive impairment $[2,3]$. Older adults with dementia are at a high risk of falling and sustaining fractures mainly because of impaired central processing leading to reduced balance and gait [4]. Dementia seems to be an independent risk factor for falling [5].

Acute pain is defined as 'pain of recent onset and probable limited duration. It usually has an identifiable temporal and causal relationship to injury or disease [6]. Under-treatment of acute pain is more likely to occur in cognitively impaired patients [7-9]. There is evidence of this in acute pain management, where older persons have not received adequate pain management during their hospitalisation $[10,11]$. Furthermore older adults with hip fracture are at risk for underassessment of pain and considerable delays in analgesic administration while pain is identified. Persons with severe or moderate dementia and hip fracture received one third the amount of opioid analgesia as cognitively intact subjects [12]. Similar findings were seen among older persons with a total hip or knee arthroplasty. The cognitively intact group received three times more opioid analgesic than the cognitively impaired group [13].

\footnotetext{
*Address correspondence to this author at the Department of Nursing Science, Kuopio Campus, University of Eastern Finland, P.O. Box 1627FIN-70211 Kuopio, Finland; Tel: +358408401515;

E-mail:momaatta@student.uef.fi
}

Proper pain management includes paying attention to human subject rights. Frail older adults with dementia lack verbal communication ability, and so are at high risk of insufficient pain management. The role of nursing staff is crucial in asserting quality care for this vulnerable patient group [14]. Insufficient pain treatment in older patients with hip fracture causes not only human suffering but longer stays in hospital, delayed ambulation and long-term functional impairment $[10,15]$.

\section{NURSING PRACTICES IN ACUTE PAIN MANAGEMENT}

Evidence-based principles to follow include providing pain medication prior to painful events (such as dressing or wound healing) [16-19], prior to physical activity [16-18] and regularly [16, 19-22], administering analgesics around the clock [16, 20-23], assessing and documenting the effect of analgesics (including side-effects) [20, 21, 23, 24], assessment for post-operative pain at least every four hours during the first days [20-21,23] and assessing pain by means of pain scales [16, 19-21, 23, 25].

Providing adequate pain medication prior to painful events (such as dressing or wound healing) is essential, because post-surgical movement associated pain is more intense $(95-226 \%)$ than pain at rest [17]. However it seems that movement associated pain has been a minor concern in managing post-surgical pain $[17,18]$.

In an acute care setting there is a need for baseline and routine follow-up pain intensity ratings at least every 4 hours to guide pain management and treatment decisions [24]. A study by Mehta and colleagues [16] found that only 7\% of 
cognitively impaired surgical patients $(62 \%$ fractures as an aetiology of acute pain) were placed on an around the clock analgesic regimen. Such limited use of around the clock analgesic administration could be explained by a lack of familiarity with, and/or application of existing evidencebased pain management guidelines.

Cognitively impaired patients are often able to self report pain scores [16, 25-27]. The golden standard for pain assessment is self reporting and it is the most reliable indicator of presence or intensity of pain [28, 29]. People with mild dementia can provide valid reports of pain, but people with more severe cognitive impairment may have difficulties doing so or be unable to clearly report pain [29]. The intensity of pain is measured for example by Visual Analogue Scale (VAS), Verbal Descriptor Scale (VRS), and Faces Scale [30]. The VAS is widely used, especially in hospital settings [25] and it consists of a $100 \mathrm{~mm}$ horizontal line with verbal anchors at both ends and no tick marks [20]. The patient is asked to mark the line and the 'score' is the distance in millimetres ( 0 to $100 \mathrm{~mm}$ ) from the left side of the scale to the mark. The VAS requires the ability to discriminate subtle differences in pain intensity and may be difficult for some older persons to complete $[20,25,30]$. A tool that has been specifically recommended for use with older adults is the Verbal Descriptor Scale (VRS) $(0=$ no pain, 4=unbearable pain) [30]. It has been tested also in older persons with mild to moderate cognitive dysfunction [25, 27]. If a person is unable to report pain verbally, one option is to assess pain through behavioural tools [28]. The Pain Assessment in Advanced Dementia Scale (PAINAD) developed by Warden et al. 2003, assesses five categorical items: breathing, negative vocalisation, facial expression, body language and consolability [31]. Items are scored from 0 (no pain) to 10 (most severe pain). Each category is scored of 0 to 2 indicating intensity of behaviour.

Herr \& Titler et al. [24] assessed 1454 medical records from patients with hip fractures and found, that although nearly all had some documentation related to pain $(99 \%)$, only $54 \%$ had pain assessed with a numeric rating scale, $4 \%$ with a non-numeric rating scale (such as verbal descriptor or faces scale), and $7 \%$ with nonverbal pain behaviours. Thus one third of patients had no assessment of pain documented.

\section{NON-PHARMACOLOGICAL TREATMENT PRACTICES IN ACUTE CARE SETTING}

Analgesics are the cornerstone of acute pain management $[17,21]$. However there are many non-pharmacological pain treatments and in an acute care setting they are used supplementary to effective pharmacological treatment methods [32, 33]. Some strategies, such as imagery or relaxation techniques, may not be feasible for cognitively impaired older adults due to communication difficulties [14]. The most frequently used non-pharmacological intervention for those hospitalised with a hip fracture includes repositioning, followed by use of pressure relief devices and cold application [16, 34].

Anxiety has been shown to be one predictive factor and is associated with a higher intensity of post-operative pain $[20,35]$. The relationship between anxiety and pain is reciprocal, so that fear exacerbates pain [35] and pain in turn appears to promote fear and anxiety [29]. Attempting to alter the patient's emotional state, from stress or fear to comfort or peace, should also be an effective feature of certain pain management practices such as therapeutic communication (e.g. quieting and consoling or soothing supportive touch) and cueing [36]. Individuals with dementia have a decreased threshold for stress from the environment, so the need for a peaceful and comfortable environment without e.g. visual, auditory or thermal stress, is highlighted [36].

The use of particular music to divert attention from pain and to promote a sense of relaxation and well-being has long been a popular approach. According to a Cochrane review, listening to music reduces pain intensity and opioid requirements after surgery, but the magnitude of benefit is small [37]. This result concurs with a prospective clinical study; listening to music has been shown to alleviate pain intensity and pain distress significantly after abdominal surgery [38]. There is little consistent evidence of benefit from massage in the treatment of post-operative pain. Evidence for benefits from post-operative local cooling is mixed. Significant reductions in opioid consumption and pain scores after a variety of orthopedic operations have been reported; other studies have shown no such reductions [20]. In one study based on the medical records of caregivers caring for hospitalised cognitively impaired patients with acute pain, the results indicated that non-pharmacological methods (such as distraction, repositioning and cold packs) were used frequently $(75 \%)$ [16].

There are some limitations to the use of nonpharmacological therapies, because the evidence base regarding the use of non-drug therapies to manage acute pain requires further development; current knowledge does not support consistent outcomes from these therapies [32]. Further research is needed to provide evidence based knowledge about the effectiveness of these methods [20,32]. The absence of evidence regarding the effects of many nonpharmacological therapies doesn't automatically mean that these methods are ineffective. It's advisable to use all safe methods which seem to be effective.

In the last decade, there has been a growing interest about pain in older people $[39,40]$. Research is needed to develop effective strategies for managing pain among older patients with dementia in the acute-care setting [19].

The purpose of this study was to describe post-operative pain management practices in hip fractured patients with dementia. We used the following research questions:

1. Which practices do the nursing staffs apply to manage post-operative pain in patients with hip fracture and dementia?

2. How are the background variables of nursing staff related to their pain management practices?

\section{MATERIALS AND METHODOLOGY}

\section{Design}

A cross-sectional design was used to develop a questionnaire and to evaluate the current situation of postoperative pain management practices for patients with dementia as evaluated by nursing staff. All university and city-centre hospitals where the incidence of first hip fractures was over 100/year were included. The 17 eligible hospitals 
treated approximately $70 \%$ of all patients admitted to hospital for hip fractures in Finland.

\section{Development of Questionnaire}

Because no questionnaire was found to assess postoperative pain management practices by nursing staff in people with dementia in an acute care setting, a new questionnaire was developed. The scale was based on previous research studies (Table 1). The pain management practices presented in this article, are part of the total "Postoperative Pain Management in Patients with Hip Fracture and Dementia" scale which exists alongside the "Pain Treatment Practices" subscale (17 items), pharmacological pain treatment, knowledge about analgesic side effects, the barriers of pain management, pain related behavioural changes, pain documentation, the most effective nonpharmacological pain treatment practices, operational preconditions for developing pain management and expectations for pain management. The first part of the questionnaire (Table 2) focussed on demographic information, including hospital, gender, age, occupation, work experience both at current employment and in health care generally, contract, employment arrangements and work shifts. Other background information (Table 3) included participation in update training, and opinions regarding the primary aim of pain management and the sufficiency of postoperative pain management. Face validity was established by asking two pain experts (one a docent in nursing science and one a professor of pharmacological medicine), one professor of nursing science and eight doctorial students to review the questionnaire. The section "post-operative pain management practices" is a part of questionnaire which was developed to measure the current situation in post-operative pain management. The whole questionnaire was pilot tested in one surgical unit $(\mathrm{n}=19)$ before use. The nursing staff stated on a separate form that all the items were clearly expressed and easy to complete. After pre-testing, the questionnaire was simplified so that an individual question asked only one thing. Additionally the scale was made easier to use by modifying its visual presentation. Nursing staff were asked how post-operative pain management practices are applied on their units when caring for patients with dementia.

\section{Procedures}

A contact person from each unit distributed the questionnaires and spoke to the participants. A cover information letter detailing the procedure was attached to the questionnaire and participants were asked to respond. The

Table 1. Questionnaire Items and Related Studies (Author(s) and Year of Publication)

\begin{tabular}{|c|c|}
\hline Questionnaire Items & Author(s) and Year of Publication \\
\hline Helping with daily activities (e.g. washing, dressing) & Herr \& Bjoro et al. 2006 [21] \\
\hline Providing pain medication regularly & $\begin{array}{l}\text { MacIntyre \& Shug et al. } 2010 \text { [20]; Mehta \&Siegler et al. } 2010 \text { [16]; Kelley, Siegler \& Reid } \\
2008 \text { [19]; Herr, Bjoro et al. } 2006 \text { [21]; Herr \&Titler et al. } 2004 \text { [22] }\end{array}$ \\
\hline Repositioning & $\begin{array}{l}\text { MacIntyre \& Shug et al. } 2010 \text { [20]; Mehta \&Siegler et al. 2010[16]; Herr \& Bjoro et al. } 2006 \\
\text { [21]; Titler \& Herr et al. } 2006 \text { [34] }\end{array}$ \\
\hline Administering analgesics around the clock & $\begin{array}{l}\text { Coker E \& Papanaioannou et al. } 2010 \text { [23]; MacIntyre \& Shug et al. } 2010 \text { [20]; Mehta } \\
\text { \&Siegler et al. } 2010 \text { [16]; Herr \&Bjoro et al. } 2006 \text { [21]; Herr \&Titler et al. } 2004 \text { [22] }\end{array}$ \\
\hline $\begin{array}{l}\text { Providing pain medication prior to painful events (such as } \\
\text { dressing or wound healing) }\end{array}$ & $\begin{array}{l}\text { Srikandarajah \& Gilron 2011[17]; Kehlet 2011[18]; Mehta \&Siegler et al. } 2010 \text { [16]; Kelley, } \\
\text { Siegler \& Reid } 2008 \text { [19] }\end{array}$ \\
\hline By using cold therapy (e.g. cold bags) for pain relief & $\begin{array}{l}\text { MacIntyre \& Shug et al. } 2010 \text { [20]; Mehta \& Siegler et al. 2010[ 16]; Herr \& Bjoro et al. } \\
2006 \text { [21]; Titler \&Herr et al. } 2006 \text { [34] }\end{array}$ \\
\hline Providing pain medication prior to physical activity & Srikandarajah \& Gilron 2011[17]; Kehlet 2011[18]; Mehta \& Siegler et al. 2010 [16] \\
\hline Quieting and consoling & Kovach \& Logan et al.2006 [36] ; Feeney 2004 [42] \\
\hline Assessment and documentation of effects of analgesics & $\begin{array}{l}\text { Coker E \& Papanaioannou et al. } 2010 \text { [23]; MacIntyre \& Shug et al. } 2010 \text { [20]; Herr \& Titler } \\
\text { 2009; Herr \& Bjoro et al. } 2006 \text { [21] }\end{array}$ \\
\hline Assessment for pain at least every four hours & $\begin{array}{l}\text { Coker E \& Papanaioannou et al. } 2010 \text { [23]; MacIntyre \& Shug et al. } 2010 \text { [20]; Herr \& Bjoro } \\
\text { et al. } 2006 \text { [21] }\end{array}$ \\
\hline Soothing, supportive touch & Kovach \& Logan et al.2006 [36] \\
\hline Assessing pain by means of pain scales & $\begin{array}{l}\text { Coker E \& Papanaioannou et al. } 2010 \text { [23]; MacIntyre \& Shug et al. } 2010 \text { [20]; Mehta \& } \\
\text { Siegler et al. } 2010 \text { [16] ; Pesonen \& Kauppila et al. } 2009 \text { [25]; Kelley, Siegler \& Reid } 2008 \\
\text { [19]; Herr \& Bjoro et al. } 2006 \text { [21] }\end{array}$ \\
\hline Presence when patient seems to be in pain & Kovach \& Logan et al. 2006 [36] \\
\hline $\begin{array}{l}\text { Peaceful and comfortable environment (e.g. quiet, lights, } \\
\text { air conditioning) }\end{array}$ & Herr \& Bjoro et al. 2006 [21]; Kovach \& Logan et al.2006 [36] \\
\hline Heat therapy (e.g. warm bags) & MacIntyre \& Shug et al. 2010 [20]; Herr \& Bjoro et al. 2006 [21] \\
\hline Music therapy & MacIntyre \& Shug et al. 2010; Cepeda \& Carr et al.2006; Herr \& Bjoro et al. 2006 \\
\hline
\end{tabular}


data collection period was March to May 2011. In April participants were reminded to fulfil the questionnaire.

\section{Data and Methods}

Pain management practices among 333 nursing staff were investigated by calculating percentages of the extent of opinions based on a five-point Likert scale ( $1=$ completely disagree, $2=$ disagree to some extent, $3=$ neither agree or disagree, $4=$ agree in some extent, $5=$ completely agree). The individual opinions are interpreted so that number 4 and 5 indicate agreement and numbers 1 and 2 disagreement. The mean sum variables, which were derived from factors, were classified into two classes in which the value $<3.5$ indicated disagreement and value $\geq 3.5$ agreement.

Research data was analysed using SPSS 17.0 for Windows (SPPS Inc., Chicago, Il, USA). Descriptive statistics were generated for the demographics of the nursing staff. The normality of distribution was analysed by means of histograms. The Two Independent Samples T-test and Analysis of Variance were used to investigate whether there were significant differences in the responses of the nurses based on background variables. Statistical significance was set at $\mathrm{P}$ value $<0.05$. Factor analysis was performed to refine the subscales (as a part of the scale development) and to investigate the underlying factor structure of each subscale [42]. Furthermore, internal consistency and reliability for the 16-item scale and associated subscales were supported by Spearman's correlation (Table 2) [42]. The responses to participants' answers about pain management practices were examined by calculating percentages of opinion for each statement. The two open-ended questions (other nonpharmacological pain management practices, and use of pain scales) were analysed by the Qualitative Data Analysis \& Research Software ATLAS.ti 6.2.25 and qualitative content analysis was performed by categorising the data to different subcategories. After that another open-ended question "which pain scales do you use when assessing post-operative pain in patients with hip fracture and dementia?" was quantified by modifying it to SPSS-data.

Factor analysis was performed to create the final questionnaire scale and to investigate its underlying factor structure. The Explanatory Factor analysis was conducted with Varimax rotation. This is method of rotation that minimizes the number of variables with high loadings on a factor, thereby enhancing the interpretability of the factors. Varimax rotation results in factors that are uncorrelated [43]. Only factors with eigenvalues greater than 1.0 were retained. The Kaiser-Meyer-Olkin measure of sampling adequacy was 0.760 so all items were retained [44], with exception of one item ("giving pain medication") because item-total correlation was below 0.2. Bartlett test of sphericity was used to test the multivariate normality of the set distributions. Asignificance value of $(\mathrm{p}<0.001)$ indicated that

Table 2. Post-Operative Pain Management Practices (Factor Structure, Factor Loadings, Correlations and Internal Consistency of Questionnaire)

\begin{tabular}{|c|c|c|c|c|}
\hline Questionnaire items & $\begin{array}{c}\text { Factor } 1 \text { Analgesic } \\
\text { Treatment } \\
\text { Practices }\end{array}$ & $\begin{array}{l}\text { Factor } 2 \\
\text { Emotional } \\
\text { Support }\end{array}$ & $\begin{array}{l}\text { Factor } 3 \\
\text { Physical } \\
\text { Methods }\end{array}$ & $\begin{array}{l}\text { Factor } 4 \\
\text { Specific } \\
\text { Methods }\end{array}$ \\
\hline $\begin{array}{l}\text { 1. Providing pain medication prior to painful events (such as dressing or wound } \\
\text { healing) }(\mathrm{n}=323)\end{array}$ & 0.711 & & & \\
\hline 2. Providing pain medication prior to physical activity ( $\mathrm{n}=322$ ) & 0.659 & & & \\
\hline 3. Assessment and documentation of effects of analgesics $(n=320)$ & 0.559 & & & \\
\hline 5. Administering analgesics around the clock $(n=321)$ & 0.416 & & & \\
\hline 6. Assessing pain by means of pain scales $(n=312)$ & 0.374 & & & \\
\hline 7. Assessment for pain at least every four hours $(n=316)$ & 0.353 & & & \\
\hline 8. Quieting and consoling $(n=323)$ & & 0.745 & & \\
\hline 12. Heat therapy (e.g. warm bags) $(\mathrm{n}=318)$ & & & 0.613 & \\
\hline 13. Peaceful and comfort environment (quiet, lights, air conditioning) $(\mathrm{n}=324)$ & & & 0.552 & \\
\hline 14. Helping with daily activities (e.g. washing, dressing) $(\mathrm{n}=327)$ & & & & 0.773 \\
\hline 15. Repositioning $(\mathrm{n}=325)$ & & & & 0.602 \\
\hline 16. By using cold therapy (e.g. cold bags) in pain relief $(n=326)$ & & & & 0.328 \\
\hline $\begin{array}{l}\text { Spearman's correlation coefficients for individual items with each subscales (for total } \\
\text { scale } 0.311-0.601 \text { ) }\end{array}$ & $0.480-0.696$ & $\begin{array}{c}0.757- \\
0.806\end{array}$ & $\begin{array}{l}0.692- \\
0.796\end{array}$ & $\begin{array}{l}0.692- \\
0.799\end{array}$ \\
\hline Eigenvalue & 3.75 & 1.85 & 1.701 & 1.306 \\
\hline
\end{tabular}

Kaiser-Mayer-Olkin measure of sampling adequacy: 0.76, Barthlett's test of sphericity significance: $\mathrm{p}<0.001$.

*Only $>0.30$ Factor loadings are presented. Extraction method is Maximum Likelihood Rotation method: Varimax with Kaiser Normalisation. 
the data did not produced an identity matrix or differ significantly from identity [44]. Internal consistency was analysed for both total scale and subscales. Table 2 presents the Spearman's correlation ranges of individual items correlations with the subscales and total scale resulting from the internal consistency analyses [42]. The four factor solution explained $53.8 \%$ of the total variance. The first factor explained $23.4 \%$, the second factor $11.6 \%$, the third factor $10.6 \%$ and the fourth factor $8.2 \%$ of the total variance. The findings indicated that the first factor was related to analgesic treatment practices in pain relieving, the second to emotional pain relieving methods, the third to the different physical manners in pain management, and the fourth to specific post-operative pain management practices in patients with dementia. The associated items are presented in Table 2.

\section{Description of the Participants}

Data was collected from nursing staff in seven university and ten city-centre hospitals in Finland $(\mathrm{N}=634)$. The questionnaires were returned by $53 \%$ of the nursing staff $(\mathrm{n}=333)$. Their mean age was $42(\mathrm{SD} \pm 11.6)$. The median of experience in their current working place was 7 years and the median of their experience in health care was 15 years. Table 3 summarises the respondent demographics.

Most of the nursing staff had not undergone any update of training concerning post-operative pain management in individuals with dementia (94\%). The primary goal in pain management was slight pain, which does not prevent normal functioning $(67 \%)$. Over half held the opinion that pain management is sufficient among patients with dementia. The other background information is presented in Table 4.

\section{RESULTS}

The results indicate that preferred methods in pain management among nursing staff were "specific pain

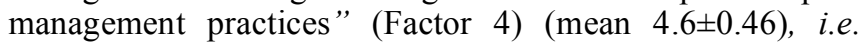
repositioning (100\%), helping with daily activities (97\%) and cold applications (93\%). The most common analgesic administration practices (mean $4.1 \pm 0.55$ ) were providing pain medication prior to painful events $(96 \%)$, prior to physical activity $(94 \%)$ and regularly $(96 \%)$. The agreement of opinion that the effects of analgesic were assessed and documented was $73 \%$. Pain was seldom assessed by means of pain scales (31\%). Quieting and consoling (85\%) was the most popular method among "emotional practices" (Factor 2 ) and presence when the patient seemed to be in pain $(42 \%)$ was the least common practice. "Physical methods" (Factor 3 ) including music therapy (6\%) and heat therapy (17\%) were not preferred pain relieving methods (mean 2.3 \pm 0.85 ), although organising a peaceful and comfort environment scored more highly (38\%). Less than one third agreed that some pain scales were in use during their work, and the most commonly used scale was VAS ( $\mathrm{n}=75$ ) (Table 8). Those who considered pain management to be sufficient thought that pain scales were in use in their unit nearly twice as often ( $40 \%$ agreement) as the group who thought that pain management was insufficient $(21 \%$ agreement $)(p<0.001)$. Tables 5 and $\mathbf{6}$ present the participant responses.
Table 3. Demographics of Nursing Staff (\%)

\begin{tabular}{|c|c|}
\hline Variable & $\%$ \\
\hline \multicolumn{2}{|l|}{ Gender $(n=333)$} \\
\hline Female & 95 \\
\hline Male & 5 \\
\hline \multicolumn{2}{|l|}{ Age $(n=330)$} \\
\hline$<36$ years & 36 \\
\hline $36-50$ years & 37 \\
\hline$>50$ years & 27 \\
\hline \multicolumn{2}{|l|}{ Occupation $(n=330)$} \\
\hline Head nurse & 2 \\
\hline Staff nurse & 5 \\
\hline Registered nurse & 76 \\
\hline Practice nurse & 15 \\
\hline Other & 2 \\
\hline \multicolumn{2}{|c|}{ Work experience in current unit $(n=329)$} \\
\hline$<5$ years & 36 \\
\hline $5-15$ years & 36 \\
\hline$>15$ years & 28 \\
\hline \multicolumn{2}{|c|}{ Work experience in health care $(n=329)$} \\
\hline$<5$ years & 14 \\
\hline $5-15$ years & 40 \\
\hline$>15$ years & 46 \\
\hline \multicolumn{2}{|l|}{ Contract $(\mathrm{n}=328)$} \\
\hline Permanent & 82 \\
\hline Deputy & 18 \\
\hline \multicolumn{2}{|c|}{ Employment arrangement $(\mathrm{n}=\mathbf{3 3 0})$} \\
\hline Fully time & 88 \\
\hline Part time & 12 \\
\hline \multicolumn{2}{|l|}{ Work shifts $(\mathrm{n}=328)$} \\
\hline Daytime jobs & 6 \\
\hline Two-shift work & 12 \\
\hline Three-shift work & 80 \\
\hline Night work & 2 \\
\hline
\end{tabular}

Because the distributions of variables were normal the parametric tests Two Independent Samples T-test and Analysis of Variance were applied to investigate whether there were significant differences in the responses of the nurses based on background variables. Statistically significant differences (Table 7) in the responses of the nurses depending on background variables were seen in "emotional pain relieving methods" as compared with gender $(\mathrm{p}=0.013)$ and participation in update training 
Table 4. Participating in Update Training, Primary Aim and Sufficiency of Pain Management (\%)

\begin{tabular}{|l|c|}
\hline \multicolumn{1}{|c|}{ Variable } & $\%$ \\
\hline \hline Participating in update training (n= 332) & 94 \\
\hline No & 6 \\
\hline Yes & 25 \\
\hline $\begin{array}{l}\text { The primary aim of post-operative pain management in patients } \\
\text { with dementia (n=325) }\end{array}$ \\
\hline Complete pain relief & 67 \\
\hline Slight pain, which does not prevent normal functioning & 3 \\
\hline Reasonable painlessness with slight discomfort & 2 \\
\hline Pain relief only at peak periods & 53 \\
\hline $\begin{array}{l}\text { Sufficiency of post-operative pain management in people with } \\
\text { dementia (n=324) }\end{array}$ & 47 \\
\hline Pain management is sufficient & \\
\hline Pain is undertreated & \\
\hline
\end{tabular}

$(p=0.035)$. Females agreed that their current working unit more often applied "emotional pain relieving methods". Those who had participated in update training thought that the uses of "emotional pain relieving methods" were more common compared with those who hadn't participated. Those who considered pain management to be sufficient also agreed that general "analgesic treatment practices" (Factor 1) $(\mathrm{p}<0.001)$ and "physical methods" (Factor 3) $(\mathrm{p}=0.007)$ were used more often in their units. Permanent staff considered that the use of "physical methods" were more unusual compared with deputy personnel $(\mathrm{p}=0.043)$. Those who were employed full time $(p=0.006)$, agreed that "specific methods" were used more often when compared with those working part time. The largest number of differences as regards pain management practices (Factors 1-3) could be seen between those working in different hospitals.

The open-ended question "Which other post-operative pain management practices in patients with hip fracture and dementia are applied in your working place?" were analysed by ATLASti-software using qualitative content analysis.

Table 5. Post-Operative Pain Management Practices Subscales (Mean, SD, \%)

\begin{tabular}{|c|c|c|c|}
\hline Subscales & Mean (Range 1-5) & SD & $\%$ of Agreement (Mean Sum Variable $\geq 3,5$ ) \\
\hline Total scale & 3.7 & 0.54 & 71 \\
\hline Specific pain management practices (Factor 4) & 4.6 & 0.46 & 98 \\
\hline Analgesic treatment practices (Factor 1) & 4.1 & 0.55 & 86 \\
\hline Emotional pain relieving methods (Factor 2) & 3.6 & 0.75 & 60 \\
\hline Physical methods (Factor 3) & 2.2 & 0.85 & 8 \\
\hline
\end{tabular}

Table 6. Nurses' Assessment of Post-Operative Pain Management Practices in Patients with Hip Fracture and Dementia (\%)

\begin{tabular}{|c|c|c|c|}
\hline Questionnaire Items & Disagree (Likert 1+2) \% & Neither Agree or Disagree (3) \% & Agree (Likert 4+5) \% \\
\hline Repositioning $(\mathrm{n}=325)$ & 0 & 0 & 100 \\
\hline $\begin{array}{l}\text { Helping with daily activities (e.g. washing, dressing) } \\
(\mathrm{n}=327)\end{array}$ & 1 & 2 & 97 \\
\hline Providing pain medication regularly $(\mathrm{n}=321)$ & 2 & 2 & 96 \\
\hline $\begin{array}{l}\text { Providing pain medication prior to painful events (such as } \\
\text { dressing or wound healing) }(n=323)\end{array}$ & 2 & 2 & 96 \\
\hline $\begin{array}{l}\text { Providing pain medication prior to physical activity } \\
(\mathrm{n}=322)\end{array}$ & 3 & 3 & 94 \\
\hline Administering analgesics around the clock $(\mathrm{n}=321)$ & 4 & 3 & 93 \\
\hline $\begin{array}{l}\text { By using cold therapy (e.g. cold bags) in pain relieving } \\
(\mathrm{n}=326)\end{array}$ & 3 & 4 & 93 \\
\hline Quieting and consoling $(n=323)$ & 4 & 11 & 85 \\
\hline $\begin{array}{l}\text { Assessment and documentation of effects of analgesics } \\
(\mathrm{n}=320)\end{array}$ & 12 & 15 & 73 \\
\hline Soothing, supportive touch $(\mathrm{n}=327)$ & 16 & 13 & 71 \\
\hline Assessment for pain at least every four hours $(\mathrm{n}=316)$ & 18 & 13 & 69 \\
\hline Presence when patient seems to be in pain $(n=329)$ & 31 & 27 & 42 \\
\hline $\begin{array}{l}\text { Peaceful and comfort environment (e.g. quiet, lights, air } \\
\text { conditioning) }(\mathrm{n}=324)\end{array}$ & 35 & 27 & 38 \\
\hline Assessing pain by means of pain scales $(n=312)$ & 51 & 18 & 31 \\
\hline Heat therapy (i.e. warm bags) $(n=318)$ & 69 & 14 & 17 \\
\hline Music therapy $(n=326)$ & 88 & 6 & 6 \\
\hline
\end{tabular}


Table 7. Differences in Nurse Responses by Gender, Participating in Update Training, Sufficiency of Pain Management, Contract, Employment Arrangement and Hospitals

\begin{tabular}{|c|c|c|c|c|c|c|c|c|c|c|c|c|}
\hline \multirow[t]{2}{*}{ Background Variable } & \multicolumn{3}{|c|}{$\begin{array}{l}\text { Analgesic Treatment } \\
\text { Practices Factor } 1\end{array}$} & \multicolumn{3}{|c|}{$\begin{array}{c}\text { Emotional } \\
\text { Support Factor } 2\end{array}$} & \multicolumn{3}{|c|}{$\begin{array}{c}\text { Physical Methods } \\
\text { Factor } 3\end{array}$} & \multicolumn{3}{|c|}{$\begin{array}{l}\text { Specific Methods } \\
\text { Factor } 4\end{array}$} \\
\hline & $\mathbf{n}$ & Mean & SD & $\mathbf{n}$ & Mean & SD & $\mathbf{n}$ & Mean & SD & $\mathbf{n}$ & Mean & SD \\
\hline \multicolumn{13}{|l|}{ Gender } \\
\hline Male & 15 & 4.0 & 0.49 & 15 & 3.2 & 0.66 & 15 & 2.1 & 1.1 & 15 & 4.7 & 0.41 \\
\hline \multirow[t]{2}{*}{ Female } & 315 & 4.0 & 0.55 & 315 & 3.7 & 0.75 & 312 & 2.2 & 0.83 & 315 & 4.6 & 0.47 \\
\hline & \multicolumn{3}{|l|}{ ns.* } & \multicolumn{3}{|c|}{$\mathrm{p}=.013$} & \multicolumn{3}{|l|}{ ns. } & \multicolumn{3}{|l|}{ ns. } \\
\hline \multicolumn{13}{|c|}{ Participating in update training } \\
\hline Yes & 20 & 4.2 & 0.43 & 20 & 4.0 & 0.63 & 20 & 2.4 & 0.83 & 20 & 4.6 & 0.57 \\
\hline \multirow[t]{2}{*}{ No } & 309 & 4.0 & 0.55 & 309 & 3.6 & 0.76 & 306 & 2.2 & 0.85 & 309 & 4.6 & 0.46 \\
\hline & \multicolumn{3}{|l|}{ ns. } & \multicolumn{3}{|c|}{$p=.035$} & \multicolumn{3}{|l|}{ ns. } & \multicolumn{3}{|l|}{ ns. } \\
\hline \multicolumn{13}{|c|}{ Sufficiency of pain management } \\
\hline Undertreated & 147 & 3.9 & 0.59 & 151 & 3.6 & 0.77 & 148 & 2.1 & 0.76 & 151 & 4.6 & 0.47 \\
\hline \multirow[t]{2}{*}{ Sufficient } & 169 & 4.2 & 0.46 & 170 & 3.6 & 0.73 & 170 & 2.3 & 0.90 & 170 & 4.7 & 0.46 \\
\hline & \multicolumn{3}{|c|}{$\mathbf{p}<.001$} & \multicolumn{3}{|l|}{ ns. } & \multicolumn{3}{|c|}{$p=.007$} & \multicolumn{3}{|l|}{ ns. } \\
\hline \multicolumn{13}{|l|}{ Contract } \\
\hline Permanent & 259 & 4.1 & 0.54 & 265 & 3.7 & 0.75 & 262 & 2.1 & 0.83 & 265 & 4.6 & 0.47 \\
\hline \multirow[t]{2}{*}{ Deputy } & 60 & 4.0 & 0.57 & 60 & 3.6 & 0.77 & 60 & 2.4 & 0.90 & 60 & 4.6 & 0.45 \\
\hline & \multicolumn{3}{|l|}{ ns. } & \multicolumn{3}{|l|}{ ns. } & \multicolumn{3}{|c|}{$p=.043$} & \multicolumn{3}{|l|}{ ns. } \\
\hline Employment arrangemen & & & & & & & & & & & & \\
\hline Fully time & 282 & 4.1 & 0.55 & 287 & 3.6 & 0.76 & 285 & 2.2 & 0.84 & 287 & 4.7 & 0.44 \\
\hline Part time & 39 & 4.0 & 0.50 & 40 & 3.5 & 0.75 & 39 & 2.1 & 0.91 & 40 & 4.4 & 0.53 \\
\hline & ns. & & & ns. & & & ns. & & & $p=.0$ & & \\
\hline Different hospitals & & & & & & & & & & & & \\
\hline All hospitals & 324 & 4.1 & 0.55 & 330 & 3.6 & 0.75 & 327 & 2.2 & 0.85 & 330 & 4.6 & 0.46 \\
\hline & $\mathrm{p}<.0$ & & & $\mathrm{p}=.0$ & & & $\mathrm{p}<.0$ & & & ns. & & \\
\hline University hospitals & 153 & 4.1 & 0.58 & 156 & 3.7 & 0.80 & 154 & 2.1 & 0.76 & 156 & 4.6 & 0.44 \\
\hline City-centre hospitals & 171 & 4.1 & 0.52 & 174 & 3.6 & 0.71 & 173 & 2.3 & 0.91 & 174 & 4.6 & 0.48 \\
\hline & ns. & & & ns. & & & ns. & & & ns. & & \\
\hline
\end{tabular}

*ns. =not significant.

When analysing the open ended questions, clear pattern of meaningful communication in pain management practices emerged (Fig. 1). The nursing staff highlighted that patients with dementia need specifically peaceful working approach in order to make feeling comfortable and peaceful. Appropriate information about what is going to happen next and informing about the cause of pain were also seen as to be part of pain management. Positive interaction included humour and trying to get the patient to move by singing together. Presence of relatives was also highlighted in order to get patient feel more peaceful. The nursing staff mentioned that patients with dementia need especially peaceful environment with small rooms. Also concrete suggestions such as proper lifting technique, mobilisation and in case of problems in swallowing the appropriate way in giving analgesics for enhancement of pain management were mentioned.

Different problems in non-pharmacologic pain management were mentioned often. Lack of resources and time to use non-pharmacological pain relieving methods and insufficient staffing were among problems related to pain management. Also the absence of means emerged in some comments. Some of the nursing staff mentioned that non pharmacological methods are ineffective in post-operative pain management and there is no evidence of effectiveness of certain therapies. One comment related that these methods work but in practice they cannot be applied because of overloaded and busy wards and there is also lack of air conditioning, music or massage. 


\begin{tabular}{|l|l|}
\hline \multicolumn{1}{|c|}{ Original Quotations } & Themes \\
\hline \hline $\begin{array}{l}\text { "Peaceful working approach", "Meaningful communication with patient, appropriate behaviour", } \\
\text { "Smooth behaviour, no sudden lifting", "If the patient cool down, it results in relaxation of the muscles } \\
\text { and as a consequence the patient will be peaceful". }\end{array}$ & Peaceful working approach \\
\hline $\begin{array}{l}\text { "Prior information e.g. when performing nursing actions or lifting up", "Discussing, explaining } \\
\text { beforehand what is going to happen next e.g. before movement, informing them about the cause of pain", } \\
\text { "Discussion and information on why the patient is in pain and how the pain will be relieved". }\end{array}$ & Informing patient \\
\hline $\begin{array}{l}\text { "The presence of relatives, prolonged, flexible visiting hours", "If possible the presence of relatives } \\
\text { because it makes patient more peaceful", "By getting in touch with relatives if the patient is unable to do } \\
\text { that", "Often the presence of relatives makes patients feel better, but also the awareness of the ability to } \\
\text { get help from nurses if necessary", "Some close person visiting in unit". }\end{array}$ & The presence of relatives \\
\hline $\begin{array}{l}\text { "Humour", "Trying to get the patient to move by singing together". } \\
\text { "The individual with dementia needs a peaceful environment, however there is a lack of small rooms and } \\
\text { high turnover", "Peaceful room if possible", "Four beds small rooms, it is impossible to afford a } \\
\text { peaceful, comfort environment". }\end{array}$ & Peaceful environment \\
\hline $\begin{array}{l}\text { "Proper lifting technique", "Mobilisation improves circulation, the pain will decrease over the course of } \\
\text { time", "Some individual articles, e.g. photos", "In case of problems in swallowing the appropriate way } \\
\text { lies in giving analgesics". }\end{array}$ & $\begin{array}{l}\text { Mobilisation Individual } \\
\text { articles The appropriate } \\
\text { way in giving analgesics }\end{array}$ \\
\hline
\end{tabular}

Fig. (1). The open ended question "Other post-operative pain management practices".

Lack of resources and time: "Primary medication, but if there is enough time, it's possible to use nonpharmacological pain relieving methods and healing", "I prefer these methods, but limited time is often the barrier", "More nursing staff in order to have time to stay close to the patient”.

The absence of means: "The means are limited", "Nonpharmacological pain relieving methods are ineffective in post-operative pain management", "These methods work, but in practice it's impossible to adopt them because of overloaded and busy wards. We have no air conditioning, no music or massage or Transcutaneous nerve stimulation (TNS)!", "There is no chance to apply non-pharmacological methods because of the small, four bedded rooms", "acute pain? - there are few non-pharmacological methods", "There is no evidence of the effectiveness of TNS or heat therapy".

The other open-ended question was a question concerned with how post-operative pain management practices were applied on the unit when caring for older adults with hip fracture and dementia. To the item "assessing pain by means of pain scales" was added the open-ended question: "What kind of pain scales do you use in pain assessment in patients with hip fracture and dementia?" (Table 8). The most often mentioned pain scale was VAS (75 related quotations). VRS (0-4 verbal rating scale) was mentioned in 66 quotations, general behavioural assessment in 83 quotations and common verbal assessment in 60 quotations. The unit of analysis (citation) was not the total comment, but the associated part of the comment e.g. "In our unit we have common practices in pain assessment; we use either NRS 010 or VRS, which is verbal rating scale. If the patient is unable to communicate, the PAINAD, behavioural pain assessment tool, is being road tested in our unit". This comment mentioned three different ways (=codes) to measure the pain: VRS, NRS and PAINAD (=tree quotations).
Table 8. Results of Open-Ended Question- what Kind of Pain Scales Do you Use in Pain Assessment for Patients with Hip Fracture and Dementia? (Total 231 Comments Including 348 Quotations)

\begin{tabular}{|l|c|}
\hline \multicolumn{1}{|c|}{ Codes } & Number of Quotations \\
\hline \hline Behavioural observation & 83 \\
\hline VAS $(0-10 \mathrm{~cm})$ & 75 \\
\hline VRS (verbal rating scale 0-4) & 66 \\
\hline Verbal assessment & 60 \\
\hline NRS (0-10) & 27 \\
\hline $\begin{array}{l}\text { Physiological functions (e.g. heart rate, } \\
\text { blood pressure, breathing rate) }\end{array}$ & 17 \\
\hline Facial pain scale & 17 \\
\hline PAINAD & 3 \\
\hline
\end{tabular}

The nursing staff also used common pain scales in combination with behavioural assessment "It depends on the degree of cognitive impairment, verbal or numerical (NRS 010) pain scales. Facial expression, motions, moaning, agitation, confusion, pain on movement or on touching a painful area, and keeping track of reactions". For non communicative patients, only one pain scale - behavioural pain assessment tool PAINAD -was mentioned (three times, from two hospitals). Instead observation of behavioural signs of pain was quite common practice among staff.

\section{DISCUSSION}

\section{Discussion of the Findings}

The results suggest that over half the nursing staff considered post-operative pain management to be sufficient among patients with hip fracture and dementia. Only one third reported that some pain scales were in use on their working unit. These results contradict previous findings in 
which only one third of patients had no objective assessment of pain documented [24]. The finding that the use of pain scales is significantly related to sufficiency of post-operative pain management $(\mathrm{p}<.001)$, warrants further examination. It is possible that there is another unknown interpretative element, which may explain the finding. The most commonly used pain scale was VAS, which is considered invalid when assessing pain in patients with moderate to severe dementia $[25,30]$. The preferred tool for pain measurement is the Verbal Rating Scale (VRS), which seems to be a valid instrument for assessment of pain in patients with mild to moderate cognitive impairment [25]. There is evidence that nurses assess pain infrequently, and rarely use pain assessment tools [41]. In this study the effects of analgesics were frequently assessed and documented (73\%) although the use of pain scales was insufficient.

Repositioning, cold therapy and helping with daily activities were commonly used methods of pain management. Medication prior to painful events (96\%) and physical activity (94\%) were also common practices. However, movement-evoked pain has not been the focus of the main post-surgical studies, according to meta-analysis conducted by Srikandarajah and Gilron (2011) [17]. Assessment of pain every 4 hours was often reported (69\%). This result contradicts previous findings where medical records after admission for acute hip fracture were assessed. Four hourly assessment was performed in $37 \%$ cases during first 24 hours and in $6 \%$ cases during first 72 hours [22]. In this study the main differences in the use of various pain management practices were between hospitals. In those hospitals where "analgesic treatment practices" were used more often, the "emotional nursing practices" were also more commonly used methods.

The nursing staffs have an important role in enabling the presence of relatives or close friends who knows the persons individual ways to express pain. Knowing the person is highlighted when trying to discover the ways that cognitively impaired individuals express the pain, because the ability to express pain is often decreased in people with dementia [14, 20, 29]. Moreover meaningful communication on behalf of staff and relatives, such as peaceful, emphatic interaction and providing appropriate information to patients by keeping them updated (e.g. about what is going to happen and the cause of their pain) is important, because anxiety and distress are in connection to post-operative pain. According to systematic review [35] it was found that anxiety is one of the most significant predictive factors for intensity of postoperative pain. Psychological distress can increase postoperative analgesic consumption. When examining the relationship between pain and negative affects in older adults following orthopaedic surgery, the only significant predictor of pain in this population was state of anxiety [45]. Skilled communication is associated with improvement in pain relief. In a cross-sectional study of nine hospitals, Gittell and colleagues (2000) found that the better the communication, the better the postsurgical pain relief [46]. Individuals with dementia have a decreased threshold for stress from the environment, so a peaceful and comfortable environment without, for example, visual, auditory or thermal stress, is highlighted [36]. A focus on "organising a peaceful and comfortable environment" was not common practice (38\% agreement) in units. On the other hand, the nursing staff also suggested that the means for staff to organise a comfortable environment is limited due to small, noisy, multi-beds room and lack of time.

Nurses are the professional group mainly responsible for assessing pain, and administering and evaluating the quality of pain relief in older people. On this basis, they are also the group most likely to affect improved patient outcomes [14, 47]. This research provides insight into the current utilisation of certain pain management practices, and the findings should be utilised for the nursing practice when planning suitable complementary educational interventions.

\section{Reliability, Validity and Trustworthiness of the Study}

This research has limitations. It was conducted using a newly developed instrument and after analysing the openended questions, new aspects in nursing practices were found, such as a peaceful working approach, facilitating the presence of relatives and providing appropriate information to patients. Secondly, the response rate was $53 \%$, which can be a risk for the potential differential dropout of subjects. Response rates between different hospitals varied greatly, so that in university hospitals the response rate was $59 \%$ and in city-centre hospitals $48 \%$. The face-validity was conducted and the questionnaire was pre-tested in only one surgical unit $(n=19)$ before use. Internal consistency and reliability for the 16-item scale was supported by Spearman's correlation [42]. Each item correlated with total scale $(\geq .311)$ and with associated four factors $(\geq .480)$. The structure validity was established by generating a Factor analysis. The four Factor solution accounted approximately $54 \%$ of the total variance.

The open-ended questions were analysed by content analysis but it is important to be aware that text always involves multiple meanings and there is always some degree of interpretation. This is an important issue when discussing the trustworthiness of findings in qualitative content analysis [48]. The primary documents were read carefully several times and the statements given under each code were checked afterwards in order to obtain objective interpretation.

\section{Ethical Considerations}

Permission to conduct the study was obtained from each hospital according their individual procedure. Ethical permission was obtained from the Ethical Committee of Northern Savo District (83/2010). Nursing staff participated in this study voluntarily and the information was obtained anonymously.

\section{CONCLUSIONS}

This pilot study produced new information about perceived nursing practices in the management of postoperative pain in patients with hip fracture and dementia. The following conclusions were drawn on the basis of study:

1. Over half the nursing staff considered post-operative pain management to be sufficient for patients with hip fracture and dementia. However, this does not delete the possibility of undertreatment, because the pain assessment is very demanding task in demented persons. 
2. The most common pain scale was VAS, which is not suitable for most people with dementia. There is a need for educational intervention, in which different pain scales and assessments of behavioural expressions of pain are implemented in practice according to the severity of cognitive impairment.

3. There is also a need to take into account the emotional aspects of pain relief for people with dementia. The presence of relatives or other close persons can help in recognising individual ways of expressing pain and provide meaningful interpersonal communication in decreasing anxiety among patients with dementia.

4. Preferred non-pharmacological methods were repositioning, cold therapy and helping with daily activities.

5. Providing pain medication prior to movement or painful events, administering analgesic regularly and around the clock were commonly used pharmacological pain relieving methods.

Based on this study, there is a need for update training for nursing staff about using different pain scales according to the degree of cognitive impairment. Educational intervention is especially reasonable because a more common use of pain scales was significantly related to a belief that post-operative pain management in this patient group was sufficient. Intervention studies are needed in order to determine how acute pain assessment among patients with hip fracture and dementia could improve. A challenge for future research includes discovering the current situation of post-operative pain management from the viewpoint of older adults with dementia e.g. by reviewing medical records concerning pain management practices or observing or interviewing them, but it could be challenging due to deficits in verbal and cognitive capacities.

\section{ACKNOWLEDGEMENTS}

This study is financially supported by University of Eastern Finland and Finnish Foundation of Nursing Education.

\section{CONFLICT OF INTEREST}

The authors declare no conflict of interest with respect to the authorship and/or publication of this article.

\section{ABBREVIATIONS}

$$
\begin{aligned}
\text { NRS }= & \text { Numeric Pain Rating Scale }(0-10) \\
\text { VRS }= & \text { Verbal Rating Scale }(0=\text { no pain, } 1=\text { slight pain, } \\
& 2=\text { moderate pain, } 3=\text { severe pain, and } 4=\text { unbearable } \\
& \text { pain }) \\
\text { VAS }= & \text { Visual Analogue Scale }(0-10 \mathrm{~cm})
\end{aligned}
$$

\section{REFERENCES}

[1] Sund R, Juntunen M, Lüthje P, et al. PERFECT-Lonkkamurtuma. Hoitoketjujen toimivuus, vaikuttavuus ja kustannukset lonkkamurtumapotilailla. [Performance, effectiveness and cost of treatment of hip fracture care episodes] STAKES 18/2008.

[2] Griffiths R, Alper J, Beckingsale A, et al. Association of Anaesthetists of Great Britain and Ireland. Management of proximal femoral fractures 2011. Anaesthesia 2012; 67: 85-98.
[3] Zakriya KJ, Christmas C, Wenz JF, Franckowiak S, Anderson R, Sieber FE. Preoperative factors associated with postoperative change in confusion assessment method score in hip fracture patients. Anesth Analg 2002; 94: 1628-32.

[4] Viramo P, Sulkava R. Muistihäiriöiden ja dementian epidemiologia. [The epidemiology of dementia]. In: Erkinjuntti T, Rinne J, Alhainen K, Soininen H. Duodecim 2006.

[5] van Doorn C, Gruber-Baldini AL, Zimmerman S, et al. Dementia as a risk factor for falls and fall injuries among nursing home residents. J Am Geriatr Soc 2003; 51(9): 1213-8.

[6] Ready LB, Edwards WT. Management of acute pain: a practical guide. Taskforce on acute pain. Seattle: IASP Publications 1992.

[7] Feldt KS, Ryden MB, Miles S. Treatment of pain in cognitively impaired compared with cognitively intact older patients with hipfracture. J Am Geriatr Soc 1998; 46: 1079-85.

[8] Forster MC, Pardiwala A, Calthorpe D. Analgesia requirements following hip fracture in the cognitively impaired. Injury 2000; 31(6): 435-6.

[9] Morrison RS, Siu AL. A comparison of pain and its treatment in advanced dementia and cognitively intact patients with hip fracture. J Pain Symptom Manage 2000; 19(4): 240-8.

[10] Morrison RS, Magaziner MA, McLaughlin G, et al. The Impact of post-operative pain on outcomes following hip fracture. Pain 2003; 103 (3): 303-11.

[11] Titler MG, Herr K, Schilling ML, et al. Acute pain treatment for older adults hospitalized with hip fracture: current nursing practices and perceived barriers. Appl Nurs Res 2003; 16 (4): 211-27.

[12] Morrison RS, Siu AL. A comparison of pain and its treatment in advanced dementia and cognitively intact patients with hip fracture. J Pain Symptom Manage 2000; 19(4): 240-8.

[13] Lynn CS, Bloom KC, McDonough JP. Pain management in the elderly: does cognitive function really matter? AANA J 2009; 77(5): 391.

[14] Kankkunen P. Dementiaoireisen ihmisen kivun hoidon hyvät käytännöt [Good practices in pain management among people with dementia]. In: Voutilainen P, Tiikkainen P, Eds. Gerontologinen hoitotyö [Gerontological nursing]. WSOY. Oppimateriaalit Oy, Helsinki 2009; pp. 247-65.

[15] Herrick C, Steger-May K, Sinacore DR, Brown M, Schechtman $\mathrm{KB}$, Binder EF. Persistent pain in frail older adults after hip fracture repair. J Am Geriatr Soc 2004; 52(12): 2062-8.

[16] Mehta SS, Siegler EL, Henderson CR, Reid MC. Acute pain management in hospitalised patients with cognitive impairment: A study of provider practices and treatment outcomes. Pain Med 2010; 11: 1516-24.

[17] Srikandarajah S, Gilron I. Systematic review of movement-evoked pain versus pain at rest in postsurgical clinical trials and metaanalyses: a fundamental distinction requiring standardized measurement. Pain 2011; 152: 1734-9.

[18] Kehlet H, Dahl JB. Assessment of post-operative pain-need for action! Pain 2011; 152: 1699-700.

[19] Kelley AS, Siegler EL, Reid MC. Pitfalls and recommendations regarding the management of acute pain among hospitalised patients with dementia. Pain Med 2008; 9(5): 581-6.

[20] MacIntyre PE, Schug SA, Scott DA, Visser EJ, Walker SM. APM: SE Working Group of the Australian and New Zealand College of Anaesthetists and Faculty of Pain Medicine, Acute Pain Management: Scientific Evidence (3rd ed). ANZCA \& FPM, Melbourne 2010.

[21] Herr K, Bjoro K, Steffensmeier J, Rakel B. Guideline: Acute pain management in older adults. Iowa City (IA): University of Iowa Gerontological Nursing Interventions Research Center, Research Translation and Dissemination Core 2006.

[22] Herr K, Titler MG, Schilling ML, et al. Evidence-based assessment of acute pain in older adults. Current nursing practices and perceived barriers. Clin J Pain 2004; 20(5): 331-40.

[23] Coker E, Papanaioannou A, Kaassalainen S, Dolovich L, Turpie I, Taniguchi A. Nurses' perceived barriers to optimal pain management in older adults on acute medical units. Appl Nurs Res 2010; 23(3): 139-46.

[24] Herr K, Titler M. Acute pain assessment and pharmacological management practices for the older adult with hip fracture: Review of ED trends. J Emerg Nurs 2009; 35: 312-20.

[25] Pesonen A, Kauppila T, Tarkkila P, Sutela A, Niinistö L, Rosenberg PH. Evaluation of easily applicable pain measurement 
tools for the assessment of pain in demented patients. Acta Anaesthesiol Scand 2009; 53: 657-64.

[26] Feldt KS, Ryden MB, Miles S. Treatment of pain in cognitively impaired compared with cognitively intact older patients with hipfracture. J Am Geriatr Soc 1998; 46(9): 1079-85.

[27] Pautex S, Herrmann F, Le Lous P, et al. Feasibility and reliability of four pain self-assessment scales and correlation with an observational rating scale in hospitalized elderly demented patients. J Gerontol A Biol Sci Med Sci 2005; 60: 524-9.

[28] Herr K, Bursch H, Ersek M, Miller L, Swafford K. Use of painbehavioral assessment tools in the nursing some. Expert consensus recommendations for practice. Gerontol Nurs 2010; 36(3): 18-28.

[29] American Geriatrics Society Panel on persistent pain in older persons. The management of persistent pain in older persons. J Am Geriatr Soc 2002; 50(6): 205-24.

[30] Horgas AL. Pain management in elderly adults. J Infus Nurs 2003; 26(3): 161-5.

[31] Warden V, Hurley A, Volicer L. Development and psychometric evaluation of the pain assessment in advanced dementia (PAINAD) scale. J Am Med Dir Assoc 2003; 4(1): 9-15.

[32] Wells N, Pasero C, McCaffery M. Improving the quality of care through pain assessment and management. Patient safety and quality: an evidence-based handbook for nurses. USA: AHRQ 2008; vol. 1: pp. 470-97.

[33] Helmrich S, Yates P, Nash R, Hobman A, Poulton V, Berggren L. Factors influencing nurses' decisions to use non-pharmacological therapies to manage patients' pain. Aust Adv Nurs 2001; 19 (1): 27-35.

[34] Titler MG, Herr K, Schilling ML, et al. Acute pain treatment for older adults hospitalized with hip fracture: current nursing practices and perceived barriers. Appl Nurs Res 2006; 16(4): 211-27.

[35] Vivian HY, Abrishami, Peng PW, Wong J, Chung F. Predictors of postoperative pain and analgesic consumption: a qualitative systematic review. Anesthesiol 2009; 111: 657-77.

[36] Kovach CR, Logan BR, Noonan PE, et al. Effects of the serial trial intervention on discomfort and behavior of nursing home residents with dementia. Am J Alzheimer's Dis Other Demen 2006; 21(3): 147-55.
[37] Cepeda MS, Carr DB, Lau J. Music for pain relief. Cochrane Database Syst Rev 2006; CD004843.

[38] Vaajoki A, Pietilä AM, Kankkunen P, Vehvilänen-Julkunen K. Effects of listening to music on pain intensity and pain distress after surgery: an intervention. J Clin Nurs 2012; 21(5-6): 708-17.

[39] Zwakhalen SMG, Hamers JPH, Abu-Saad HH, Berger MPF. Pain in elderly people with severe dementia: a systematic review of behavioural pain assessment tools. BMC Geriatrics 2006; 6: 3.

[40] de Andrade DC, de Faria JW, Caramelli P, et al. The assessment and management of pain in the demented and non-demented elderly patient. Arquivos de Neuro-Psiquiatria 2011; 69(2B): 38794.

[41] Eid T, Bucknall T. Documenting and implementing evidence-based postoperative pain management in older patients with hip fracture. J Orthop Nurs 2008; 12: 90-8.

[42] Burns N, Grove SK. The practice of nursing research. Appraisal, synthesis and generation of evidence. $6^{\text {th }}$ ed. USA: Elsevier/ Saunders 2009.

[43] Watson R, Thompson DR. Use of factor analysis in Journal of Advanced Nursing: literature review. J Adv Nurs 2006; 55(3): 33041 .

[44] Kim J, Mueller C. Factor Analysis. London: Sage Publications 1978.

[45] Feeney SL. The relationship between pain and negative affect in older adults: anxiety as a predictor of pain. J Anxiety Disord 2004; 18: 733-44.

[46] Gittell JH, Fairfield K, Bierbaum B, et al. Impact of relational coordination on quality of care, post-operative pain and functioning, and length of stay: a nine-hospital study of surgical patients. Med Care 2000; 38(8): 807-19.

[47] Prowse M. Post-operative pain in older people: a review of the literature. J Clin Nurs 2006; 16: 84-97.

[48] Graneheim UH, Lundman B. Qualitative content analysis in nursing research: concepts, procedures and measures to achieve trustworthiness. Department of Nursing, Umeå University. Umeå. Nurse Educ Today 2004; 24: 105-12.

(C) Rantala et al.; Licensee Bentham Open.

This is an open access article licensed under the terms of the Creative Commons Attribution Non-Commercial License (http://creativecommons.org/licenses/by$\mathrm{nc} / 3.0 /$ ) which permits unrestricted, non-commercial use, distribution and reproduction in any medium, provided the work is properly cited. 